\title{
Maternal nutrient restriction alters renal development and blood pressure regulation of the offspring
}

\author{
Kathryn A. Brennan ${ }^{1,2 *}$, David M. Olson ${ }^{2}$ and Michael E. Symonds ${ }^{1}$ \\ ${ }^{1}$ Centre for Reproduction and Early Life, Institute of Clinical Research, University Hospital, Nottingham NG7 2UH, UK \\ ${ }^{2}$ Perinatal Research Centre, Departments of Obstetrics and Gynecology, Pediatrics and Physiology, University of Alberta, \\ Edmonton, Alberta T6G 2S2, Canada
}

\begin{abstract}
Studies have shown that the risk of hypertension in adulthood can be affected by the in utero environment. It is established that hypertension is linked to compromised kidney function and that factors affecting organogenesis can increase the risk of later disease. Prostaglandins (PG) and growth factors are known to play an important role in regulating kidney function and renal organogenesis. The extent, however, to which global energy restriction (where all nutrients are reduced) of the mother can programme later blood pressure control or renal PG and growth factor status is unknown. A study is described that aimed to examine the long-term effects of maternal nutrient restriction (NR) and elucidate their relationship with compromised kidney development. First, it was necessary to establish animal models. A sheep model of 50\% NR during specific stages of gestation was used to investigate fetal renal development, whilst a rat model of $50 \%$ NR throughout pregnancy was used to investigate postnatal kidney development and adult functioning. Molecular analysis has shown that expression of the growth hormone-insulin-like growth factor (GH-IGF) axis is affected by NR in the fetal sheep kidneys, and that changes are dependent on the timing of NR and whether the fetus is a singleton or a twin. Analysis of the kidneys from the rat model has shown nutritional differences in the expression of PG receptors and the enzymes responsible for PG synthesis and degradation that persist into adulthood. In conclusion, NR does affect the GH-IGF and PG axes, and these changes may be important in the nutritional programming of renal functioning and adult blood pressure control.
\end{abstract}

Maternal nutrient restriction: Blood pressure: Kidney development: Prostaglandin axis: Growth hormone-insulin-like growth factor axis

\section{Fetal programming}

CVD is a major cause of mortality and morbidity in the Western world and hypertension is one of the main risk factors. Whilst adult lifestyle and diet undoubtedly play major roles in determining who is affected, there is an increasing body of evidence to suggest that the in utero environment is also involved. The incidence of CVD is not uniform across the UK, with mortality being highest in the North-west and lowest in the South-east (Knox, 1973; Fulton et al. 1978; Pocock et al. 1980). It has been found that individuals born in a high-risk area still have an increased risk even if they move to an area with lower risk (Osmond et al. 1990). It would seem, therefore, that the risk of CVD is determined, at least in part, by the place of birth and consequently moves with the individual.

Many retrospective studies have been carried out on medical records to examine the relationship between birth weight and both CVD in general (Barker, 2002) and hypertension specifically (Barker et al. 1990). Hypertension is linked to impaired development of the kidney, in particular a reduction in nephron number (Mackenzie \& Brenner, 1995). There is some evidence from human observational studies that the uterine environment can affect the growth of the kidneys. This evidence includes a study by Konje et al. (1996), which has found that slowly-growing fetuses have disproportionately small kidneys. Similarly, intrauterine growth restriction decreases nephron number in

\footnotetext{
Abbreviations: COX, cyclooxygenase; EP, E-prostanoid; GH, growth hormone; IGF, insulin-like growth factor; NR, maternal nutrient restriction; PG, prostaglandin.

*Corresponding author: Kathryn Brennan, fax +44 115970 9382, email mgxkb@nottingham.ac.uk
} 
Table 1. The effects of maternal nutrient restriction on blood pressure of the offspring investigated using rat and sheep models

\begin{tabular}{lllccll}
\hline Species & Restriction & $\begin{array}{c}\text { Measurement } \\
\text { technique }\end{array}$ & Result & $\begin{array}{c}\text { Age at } \\
\text { measurement } \\
\text { (weeks) }\end{array}$ & Gender & Reference \\
\hline Sheep & Energy & Catheter & $\downarrow$ & 26 & $\mathrm{M}$ and F & Gopalakrishnan et al. (2005) \\
Sheep & Energy & Catheter & $\uparrow$ & 156 & $\mathrm{M}$ & Gopalakrishnan et al. (2004) \\
Rat & Protein & Tail cuff & $\uparrow$ & 6 & $\mathrm{M}$ & Gardner et al. (1997) \\
Rat & Protein & Tail cuff & $\uparrow$ & 4 & $\mathrm{M}$ and F & McMullen et al. (2004) \\
Rat & Protein & Telemetry & $\uparrow$ & 13 & $\mathrm{M}$ & Tonkiss et al. (1998) \\
Rat & Protein & Telemetry & $=$ & 52 & $\mathrm{M}$ and F & Jensen et al. (2005) \\
Rat & Protein & Telemetry & $=$ & 21 & $\mathrm{~F}$ & Woods et al. (2005) \\
Rat & Energy & Catheter & $\uparrow$ & 28 & M and F & Ozaki et al. (2001) \\
Rat & Energy & Tail cuff & $\uparrow$ & 6 & $\mathrm{M}$ and F & Franco et al. (2002) \\
\hline
\end{tabular}

M, male; F, female; $\uparrow$, increased; $\downarrow$, decreased; =, no difference in blood pressure compared with control.

infants (Hinchliffe et al. 1992). It is not possible, however, to determine from these studies the extent to which nutrition is responsible for the outcomes described.

The use of animal nutritional intervention studies has enabled more controlled investigations of maternal diet and kidney development. Reduced kidney size and impaired nephron development have been found in rats following both protein-specific (Langley-Evans et al. 1999) and global energy (Lucas et al. 1997) restriction (where all nutrients are reduced). Another study carried out in sheep has found that global energy restriction during early to mid gestation actually increases organ size at birth and also affects kidney shape (Whorwood et al. 2001), and these offspring subsequently have lower nephron numbers (Gopalakrishnan et al. 2005). These differences in outcome are likely to be a result of species-specific differences in the timing of kidney development.

Ovine kidney development is similar to that of man in that the total number of nephrons is determined before birth. In sheep nephrogenesis is complete at approximately gestational day 130 (Moritz et al. 2003) of a $147 \mathrm{~d}$ pregnancy, whilst in man it is complete at approximately week 32 of a 38-week pregnancy (Potter, 1972). Renal development is timed differently in the rat, which has only approximately $20 \%$ of its total nephron complement formed before birth. Nephrogenesis then continues after birth, finishing at approximately postnatal day 8 (Moritz et al. 2003). Thus, these characteristics make the sheep a good animal model for investigating the effects of nutrient restriction during different periods of gestation, whilst the rat is a useful model for studying animals at different time points of kidney development, since it is possible to use littermates from the same pregnancy.

There is also evidence from animal models that nutrient restriction can alter kidney function in adult offspring. In the majority of studies kidney function has not been measured directly but effects have been seen on the animal's blood pressure, suggesting that regulatory mechanisms are disrupted. Table 1 summarises the findings of some previous studies. In sheep global energy restriction has been shown to be associated with reduced blood pressure at 6 months of age (Gopalakrishnan et al. 2005) but increased blood pressure at 3 years of age
(Gopalakrishnan et al. 2004), suggesting that age at measurement is an important factor when determining the effects of a nutritional insult. Several studies have shown that a maternal low-protein diet in the rat leads to an increase in blood pressure of approximately $23 \mathrm{mmHg}$ in the offspring when measured by the tail-cuff technique (Langley \& Jackson, 1994; Gardner et al. 1997; McMullen et al. 2004). When blood pressure is measured by telemetry, however, there is either a smaller increase in pressure of approximately $4.5 \mathrm{mmHg}$ (Tonkiss et al. 1998) or no significant difference is found (Jensen et al. 2005), suggesting that the method of measurement is important. This effect may be gender specific because no significant difference in blood pressure has been found for female animals (Woods et al. 2005). Finally, global energy restriction has also been found to increase blood pressure in rats (Ozaki et al. 2001; Franco et al. 2002), although this finding has yet to be confirmed by telemetry. In addition, Franco et al. (2002) have found that both glomerular filtration rate and renal plasma flow are reduced in animals that are nutrient restricted, in combination with an acceleration of glomerularsclerosis.

The mechanisms and mediators responsible for translating energy or protein restriction during pregnancy into altered blood pressure in adult offspring are undefined. The overall purpose of the studies to be described was, therefore, to examine the effects of undernutrition on two potential mediators of nephron development, the growth hormone (GH)-insulin-like growth factor (IGF) axis and prostaglandins $(\mathrm{PG})$ in the developing kidney.

\section{Growth hormone-insulin-like growth factor axis}

The main components of the GH-IGF axis are summarised in Fig. 1(a). GH stimulates production of IGF-I via the GH receptor and is known to be the major stimulus for IGF-I production in the adult kidney, although its role in the fetus is less clear (Hammerman, 1989). IGF-I and -II can both bind to the IGF-I receptor and stimulate growth. IGF-II can also bind to the IGF-II receptor, which acts as a scavenger, removing excess IGF-II from the system (Hammerman, 1989). 
(a)

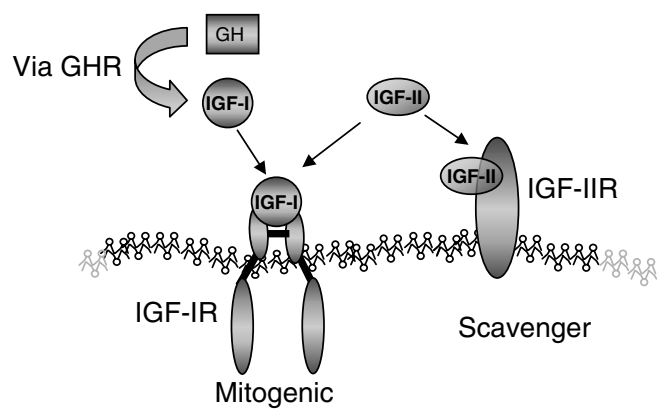

(b)

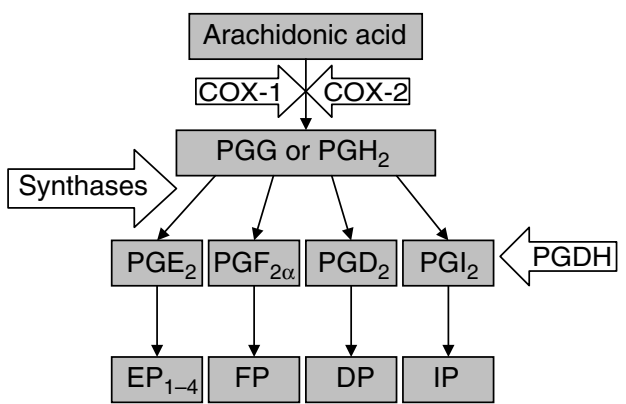

Fig. 1. (a) The growth hormone (GH)-insulin-like growth factor (IGF) axis. R, receptor. (Adapted from Hyatt et al. 2004.) (b) The prostaglandin (PG) axis. COX, cyclooxygenase; EP, FP, DP, IP, E-, F-, D-, I-prostanoid receptors respectively; PGDH, PG dehydrogenase.

\section{Rationale for the investigation}

The effects of maternal nutrient restriction (NR) on the GH-IGF axis have been investigated because it is known to play an important role in kidney development. Both the GH receptor and IGF-I are expressed at very high levels in the developing kidney, suggesting that they are important (Ymer \& Herington, 1992). IGF-I is first detectable at approximately gestational day 11 in the rat, rising 8.6-fold during the subsequent $48 \mathrm{~h}$ (Hammerman, 1989). This timing coincides with that of metanephric differentiation, indicating that IGF-I may play a primary role. IGF-I is also produced by metanephroi cultures and blocking its expression with either antibodies or oligonucleotides prevents further growth or development (Wada et al. 1993). A similar effect is seen with the addition of antibodies or oligonucleotides specific for IGF-II (Hammerman \& Miller, 1993). In addition, animals with the IGF-I gene knocked out have severely-impaired renal development (Rogers et al. 1999).

As well as a role in kidney development there is evidence to suggest that the GH-IGF axis can also affect kidney function. Infusion of GH into normal adult human subjects causes an increase in both glomerular filtration rate and renal plasma flow. This effect is only found once $\mathrm{GH}$ levels have returned to normal, but whilst plasma IGF-I is still elevated, suggesting this effect is indirect (Parving et al. 1978).
The fetal and adult GH-IGF axis is nutritionally sensitive. For example, NR affects IGF-I and -II expression in both the liver and skeletal muscle (Brameld et al. 2000), whilst kidneys from growth-restricted sheep fetuses have greater sensitivity to GH infusion (Bauer et al. 2003) than normally-growing controls (Bauer et al. 2000). Importantly, abnormalities within the GH-IGF axis have been found in many of the adult diseases associated with low birth weight (Holt, 2002).

\section{Animal model utilised}

In order to investigate the effects of NR on the GH-IGF axis a sheep model was established, the design of which is illustrated in Fig. 2(a). Briefly, sheep were randomly allocated to one of five groups on the day of mating (nine to sixteen per group). The control group (group 1) was fed $100 \%$ of their metabolisable energy requirements throughout the experiment. Groups 2-4 were restricted to eating $50 \%$ of their metabolisable energy requirements from gestational days $0-30,31-65$ and 66-110 respectively. Group 5 was nutrient restricted throughout the experiment. At $110 \mathrm{~d}$ of gestation all animals were killed and the fetal kidneys sampled. In all five groups there were both singleton and twin pregnancies. RT-PCR was used to measure the mRNA abundance of the components of the GH-IGF axis. (a)

\begin{tabular}{l|l|l|l|}
\multicolumn{1}{c}{$0-30 \mathrm{~d}$} & \multicolumn{1}{c}{$31-65 \mathrm{~d}$} & \multicolumn{1}{c}{$66-110 \mathrm{~d}$} \\
\cline { 2 - 4 } Group 1 & & & \\
\cline { 2 - 4 } Group 2 & & & \\
\cline { 2 - 4 } Group 3 & & & \\
\cline { 2 - 4 } Group 4 & & & \\
\cline { 2 - 4 } Group 5 & & & \\
\cline { 2 - 4 } & & &
\end{tabular}

(b)

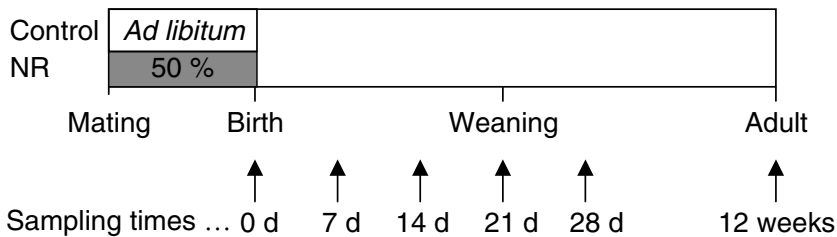

Fig. 2. (a) Sheep model design for investigating the effects of maternal nutrient restriction (NR) during different periods of gestation. ( $\square$ ), $100 \%$ metabolisable energy requirements; $(\square), 50 \%$ metabolisable energy requirements. (b) Rat model design for investigating the effects of NR at different time points of kidney development. From conception to birth the controls $(\square)$ were allowed ad libitum access to food, while the NR group $(\square)$ was fed $50 \%$ of the amount eaten by the control group. After birth and for the duration of the experiment all animals were allowed ad libitum access to food. 


\section{Nutritional effects on fetal kidney development}

It was found that kidney or body weights of the fetuses are not affected by NR (Brennan et al. 2005). This finding differs from that of Whorwood et al. (2001), who have reported an enlargement of kidney size. This disparity may be because the latter study sampled the kidneys of newborn lambs and their increased size may have been related to an acceleration of kidney growth after $110 \mathrm{~d}$ of gestation. The only effect of NR on GH-IGF expression in singleton animals is an increase in the expression of the IGF-I receptor in animals from group 4 (Brennan et al. 2005). Interestingly, this increase is not seen in animals that were nutrient restricted throughout the experiment, suggesting that it is the switch from a well-fed diet to a restricted diet that is the trigger; a similar finding has been reported in relation to the nutritional programming of fetal adipose tissue and liver development (Brameld et al. 2000; Bispham et al. 2003).

Examination of the expression of the GH-IGF axis in twin animals has shown that expression of all the genes is lower in twins compared with singleton animals, but only in animals that have been previously nutrient restricted (Brennan et al. 2005). This finding suggests that there is a combined effect of being a twin and being nutrient restricted. Similar results have been found in studies of the hypothalamic-pituitary-adrenal axis of twin sheep fetuses (Edwards \& McMillen, 2002). There is also some evidence that growth-restricted twin sheep have a reduction in nephron number compared with singletons (Mitchell et al. 2003). Given that the GH-IGF axis is one of the key regulators of the nephron complement it is quite possible that changes in expression of the axis are involved. A possible explanation for why twin fetuses may respond differently from the effects of NR is that they experience a different maternal endocrine environment from that of singleton fetuses (Budge et al. 2003) and maturation of the fetal hypothalamic-pituitary-adrenal axis is delayed (Gardner et al. 2004a).

\section{Summary}

This model of NR has no effect on kidney size at the time of sampling ( $110 \mathrm{~d}$ of gestation). This finding does not preclude the possibility that kidney growth might be affected later in gestation, which indeed appears to be the case (Whorwood et al. 2001). NR also appears to have a time-dependent stimulatory effect on the IGF-I receptor in the kidneys of singleton fetuses, an effect that is not seen in twin animals. As a consequence twins may be protected from some of the adverse effects of exposure to a reduction in maternal food intake, which may explain why blood pressure control can be similar between singleton and twin offspring in later life despite in utero competition (Gardner et al. 2004b; Gopalakrishnan et al. 2005).

\section{Prostaglandins}

The kidneys are major sites of both PG synthesis and catabolism (Gleason, 1987); the major components of the PG axis are illustrated in Fig. 1(b). The first step in the pathway is the conversion of arachidonic acid to $\mathrm{PGH}_{2}$. This reaction is catalysed by the cyclooxygenase (COX) enzyme, of which there are two isoforms, 1 and 2. The subsequent step forms the different types of PG by the actions of several specific synthase enzymes (Campean et al. 2003). The main PG in the kidney is $\mathrm{PGE}_{2}$ (Gleason, 1987), which has four different receptors (E-prostanoid $\left.(E P)_{1-4}\right)$ that elicit different responses when activated (Audoly et al. 1999). All PG are degraded by the same enzyme, PG dehydrogenase, which catalyses the oxidation of the 15-hydroxyl group making them inactive (Nasjletti et al. 1984; Johnson et al. 2004).

\section{Rationale for the investigation}

PG have an established role in regulating kidney function through modulations of vascular tone, water and ion absorption and also renin release (Breyer \& Breyer, 2000; Jensen et al. 2001). Inhibiting PG synthesis affects fetal renal function, altering renal blood flow and increasing urine osmolarity (Matson et al. 1981). Recent studies suggest that $\mathrm{PG}$ has a direct role in regulating kidney development. Because, COX-2 has a very specific pattern of expression during organ development (Vio et al. 1999; Ogawa et al. 2001; Madsen et al. 2004), disruption of which, either by the use of COX inhibitors (Komhoff et al. 2000) or by gene knock-out (Dinchuk et al. 1995), reduces the total number of nephrons formed and those formed can be abnormal.

In contrast to the GH-IGF axis the effects of NR on PG have not been well investigated. One study (Williams et al. 2002) has shown that a model of placental restriction throughout pregnancy in sheep increases the expression of both COX-2 and $\mathrm{EP}_{2}$ mRNA in the offspring's kidney. It has, however, been suggested that these effects are a result of fetal hypoxia rather than nutrient deficiency. Feeding a low-protein diet to rats through pregnancy decreases PG dehydrogenase activity and increases $\mathrm{PGE}_{2}$ excretion in the offspring (Sherman et al. 1999). The effects of a maternal global energy restriction on PG have yet to be investigated.

\section{Animal model utilised}

A rat model was used to study the PG axis because: (1) rats are litter bearing, which means it is possible to determine effects on PG expression at a range of time points in pups from the same pregnancy; (2) rats have a shorter lifespan, which means that the outcome in relation to the adult kidney can be established over a relatively short experimental time period.

The study design is summarised in Fig. 2(b). From conception to birth the controls were allowed ad libitum access to food, while the NR group was fed $50 \%$ of the amount eaten by the control group. After birth and for the duration of the experiment all animals were allowed ad libitum access to food. Animals from each litter were killed shortly after birth, then further animals were killed at postnatal days $7,14,21,28$ and at 12 weeks of age. 


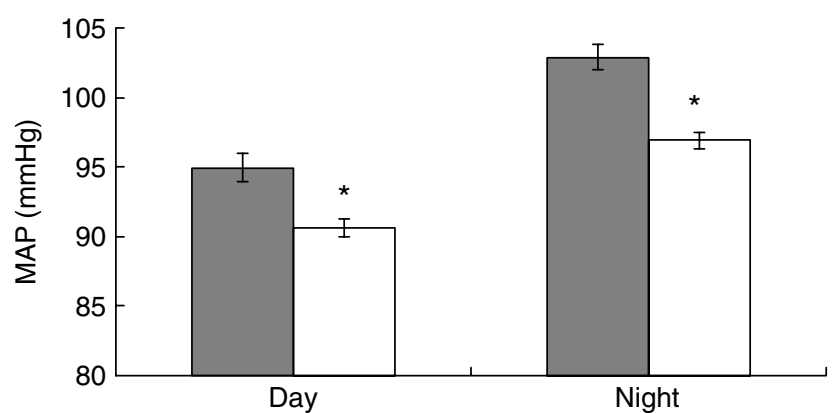

Fig. 3. The effect of maternal nutrient restriction (NR) on mean arterial pressure (MAP) in adult male rats. From conception to birth the controls $(\square)$ were allowed ad libitum access to food, while the NR group ( $\square$ ) was fed $50 \%$ of the amount eaten by the control group. After birth and for the duration of the experiment all animals were allowed ad libitum access to food (for details of the model design, see Fig. 2(b)). Values are means with their standard errors represented by vertical bars. Mean values were significantly different from those for the controls: ${ }^{\star} P<0 \cdot 05$.

\section{Nutritional effects}

Kidney weight in the NR group was found to be significantly decreased at birth and at postnatal days 7 and 14, whereas total body weight is only reduced at birth (KA Brennan, DM Olson and ME Symonds, unpublished results). Surprisingly, NR was found to have no effect on any other major organ size, confirming that the kidneys are particularly sensitive to NR.

Using the adult males to measure the effect of NR on offspring blood pressure it was found that mean arterial pressure in the NR group is significantly lower than that of the controls $(P<0 \cdot 05$; Fig. 3$)$. These findings differ in some aspects from those reported previously following global nutrient or protein restriction (see Table 1), with the most likely explanation being the method used to measure blood pressure, i.e. telemetry $v$. tail cuff.

The present model of NR affects the expression of the COX-2 enzyme, as summarised in Fig. 4. The expression pattern for controls follows that previously reported (Vio et al. 1999; Ogawa et al. 2001; Madsen et al. 2004) but is altered in NR offspring for which expression is significantly $(P<0 \cdot 05)$ reduced at postnatal days 14 and 28 compared with the controls. Given the importance of the COX-2 expression pattern for renal development, these changes could be highly disruptive to later kidney function. In contrast, $\mathrm{COX}-2$ expression is significantly $(P<0 \cdot 05)$ raised in the NR adults compared with the controls. COX expression and its relationship with blood pressure have been widely investigated and meta-analyses of these results have found that $\mathrm{COX}$ inhibitors elevate blood pressure (Pope et al. 1993; Johnson et al. 1994). This finding has not been supported by more recent studies (Catella-Lawson et al. 1999; Dilger et al. 2002; Gertz et al. 2002), and in the study of Pope et al. (1993) raised blood pressure was found only in those animals that were hypertensive before the administration of the inhibitors. The increase in COX-2 expression in the animals from the present rat model, coupled with their reduced blood pressure, would support a role for COX in blood pressure

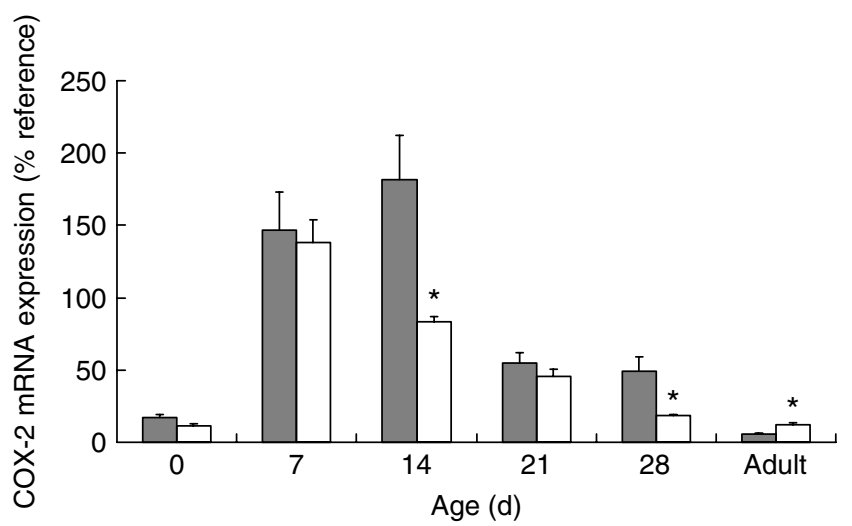

Fig. 4. The effect of maternal nutrient restriction (NR) on rat kidney cyclooxygenase (COX)-2 mRNA expression. From conception to birth the controls $(\square)$ were allowed ad libitum access to food, while the NR group ( $\square$ ) was fed $50 \%$ of the amount eaten by the control group. After birth and for the duration of the experiment all animals were allowed ad libitum access to food (for details of the model design, see Fig. 2(b)). Data were calculated as a percentage of a single reference sample. Values are means with their standard errors represented by vertical bars. Mean values were significantly different from those for the controls: ${ }^{\star} P<0.05$.

regulation. In addition, the $\mathrm{PGE}_{2}$ content of adult kidneys was found to be reduced in NR offspring (KA Brennan, DM Olson and ME Symonds, unpublished results), suggesting that either the increase in COX expression does not increase PG synthesis or that the rate of degradation is also enhanced. This finding is surprising because previous studies have found that $\mathrm{PGE}_{1}$ administration leads to an increase in blood pressure (Kailasam et al. 1994; Ishibe et al. 1998).

Effects on the expression of the EP receptors were also found, as summarised in Table 2. With the exception of $\mathrm{EP}_{1}$ expression patterns of all these receptors are affected by NR. Interestingly, there are no differences in expression at days 0 and 7, immediately following the insult and during the time when the kidneys were growth retarded, but the differences persist into adulthood. The $\mathrm{EP}_{2}$ receptor acts to stimulate water and salt re-absorption in the kidney, so reduced expression would lower re-absorption, thereby decreasing blood pressure. Indeed, $\mathrm{EP}_{2}$ receptor knock-out mice have reduced blood pressure (Tilley et al. 1999).

Table 2. Kidney E-prostanoid (EP) receptor expression in rat pups whose mothers had been nutrient restricted during pregnancy $\dagger$

\begin{tabular}{lllllll}
\hline Postnatal & & & & & & \\
day ... & 0 & 7 & 14 & 21 & 28 & Adult \\
\hline $\mathrm{EP}_{1}$ & & & & & \\
$\mathrm{EP}_{2}$ & & $\uparrow^{*}$ & & & $\downarrow^{*}$ \\
$\mathrm{EP}_{3}$ & & & & & $\downarrow^{*}$ & $\uparrow^{*}$ \\
$\mathrm{EP}_{4}$ & & & $\uparrow^{*}$ & & $\downarrow^{*}$ & $\downarrow^{*}$
\end{tabular}

$\uparrow$, Increase; $\downarrow$, decrease.

Receptor expression was significantly different from that of the controls: ${ }^{\star} P<0.05$.

†From conception to birth the controls were allowed ad libitum access to food, while the NR group was fed $50 \%$ of the amount eaten by the control group. After birth and for the duration of the experiment all animals were allowed ad libitum access to food (for details of the model design, see Fig. 2(b)). 
Conversely, activation of the $\mathrm{EP}_{3}$ receptor decreases salt and water re-absorption so increased expression of this receptor would have the same outcome. Finally, reduced expression of the $\mathrm{EP}_{4}$ receptor could reduce renin levels (Schweda et al. 2004) and therefore reduce angiotensin II and blood pressure (Lemmer et al. 2000).

\section{Summary}

The present model of NR clearly affects kidney growth, an effect that is not seen in the other organs examined. There are also changes in the PG axis of these animals that persist into adulthood. Whilst the decrease in $\mathrm{PGE}_{2}$ content might suggest an increase in systemic blood pressure, the increased COX-2 expression and changes in EP expression could explain the reduction in blood pressure seen in this model.

\section{Possible mechanism by which maternal nutrient restriction programmes kidney development}

Having established that NR can affect both the GH-IGF axis and PG in the kidney it was important to determine how these changes were mediated. Glucocorticoids are a candidate mechanism because other studies have previously found that they are affected by NR. A low-protein diet in rats has been found to increase renal expression of the glucocorticoid receptor (Bertram et al. 2001) and a similar result has been found following global NR in sheep (Whorwood et al. 2001). Cortisol treatment during pregnancy has also been linked with increased blood pressure in the adult offspring (Dodic et al. 2002). Recent studies of rats with raised blood pressure following dexamethasone treatment have found a similar rise in blood pressure in animals pair fed to the dexamethasone group (Woods \& Weeks, 2005). This finding suggests that programming by glucocorticoids and maternal nutrition may share a common mechanism. To this extent NR during late gestation in rats causes the fetus to be overexposed to maternal glucocorticoids (Lesage et al. 2001) and glucocorticoids have been shown to be essential in maintaining hypertension programmed by a maternal low-protein diet (Gardner et al. 1997).

The GH-IGF axis can be regulated by glucocorticoids through changes in gene transcription and receptor abundance (Hochberg, 2002), as can PG expression (GoppeltStruebe, 1997). Adrenalectomy increases both COX-2 expression and activity in the renal cortex, an effect that is reversed with replacement corticosterone (Zhang et al. 1999). In rats the postnatal decrease then subsequent increase in circulating corticosterone is responsible for the developmental expression pattern of renal COX-2 (Vio et al. 1999; Madsen et al. 2004). Infusion of cortisol into fetal sheep during nephrogenesis, however, has no effect on the expression of $\mathrm{COX}-2, \mathrm{EP}_{2}$ or $\mathrm{EP}_{4}$ in the kidney (Williams et al. 2004).

Glucocorticoids were found to be altered in both models of NR described earlier. Twin fetuses from the sheep model were found to have significantly $(P<0.05)$ lower expression of mRNA for the glucocorticoid receptor

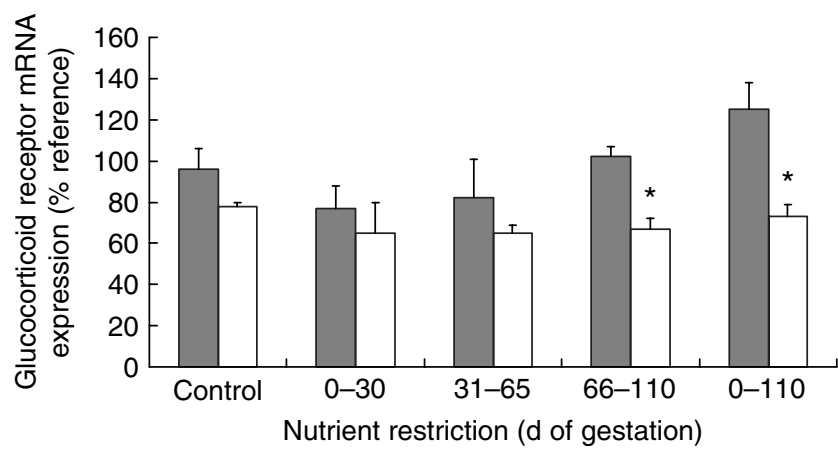

Fig. 5. The effect of maternal nutrient restriction $(50 \%$ metabolisable energy requirements) and no. of fetuses (singletons $(\square)$ and twins $(\square)$ ) on sheep kidney glucocorticoid receptor mRNA expression (for details of the model design, see Fig. 2(a)). Data were calculated as a percentage of a single reference sample. Values are means with their standard errors represented by vertical bars. Mean values were significantly different from those for the single fetus: ${ }^{*} P<0.05$.

following NR from 66 to $110 \mathrm{~d}$ of gestation and from 0 to $110 \mathrm{~d}$ of gestation (Fig. 5). This finding might explain the differences in GH-IGF expression seen in these two groups, but it does not explain the variation in the other groups, or why the IGF-IR receptor is affected in singletons and is altered only in the groups that were subjected to NR on days $0-65 \mathrm{~d}$ of gestation and not in the group nutrient restricted from 0 to $110 \mathrm{~d}$ of gestation. It seems unlikely, therefore, that glucocorticoids are the only mechanism involved. In the rat model glucocorticoid receptor expression was found to be unaffected by NR (KA Brennan, DM Olson and ME Symonds, unpublished results), but offspring were found to exhibit raised plasma corticosterone at postnatal days 14 and 28 and in adulthood (Fig. 6). This increased corticosterone could explain the reduced expression of COX-2 at days 14 and 28 because corticosterone inhibits cortical COX-2 (Zhang et al. 1999).

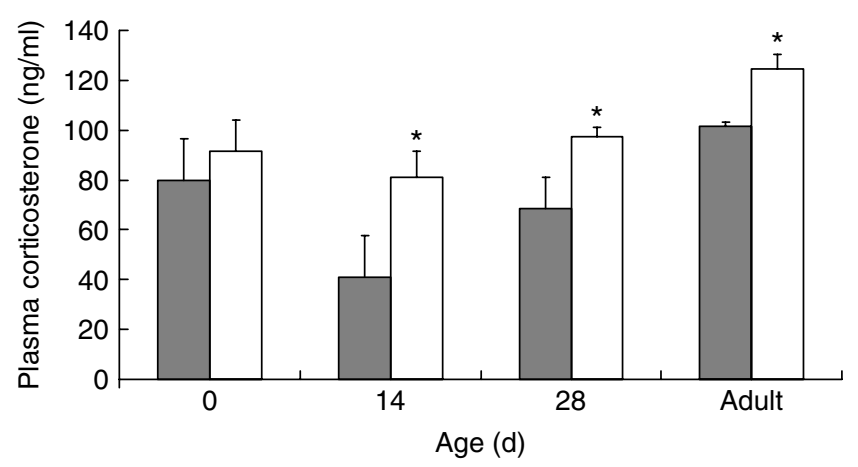

Fig. 6. The effect of maternal nutrient restriction (NR) on rat plasma corticosterone. From conception to birth the controls ( $\square$ ) were allowed ad libitum access to food, while the NR group $(\square)$ was fed $50 \%$ of the amount eaten by the control group. After birth and for the duration of the experiment all animals were allowed ad libitum access to food (for details of the model design, see Fig. 2(b)). Values are means with their standard errors represented by vertical bars. Mean values were significantly different from those for the controls: ${ }^{*} P<0.05$. 
The raised corticosterone in adult animals could also explain the increase in COX-2 in these animals because corticosterone can stimulate medullary COX-2 (Zhang et al. 2002). Studies have found that medullary COX-2 is very low in weanling rats but is greatly increased in adults (Yao et al. 2005). The time points measured in the present model suggest that this difference in the location of COX-2 expression occurs after day 28 but before 12 weeks of age.

Whilst glucocorticoids can regulate both the GH-IGF axis and PG in the kidney and these changes might be involved in the altered development and function following $\mathrm{NR}$, it is possible for glucocorticoids to affect kidney function directly, for example, by regulating levels of ion pumps in nephrons (Devarajan \& Benz, 2000). Glucocorticoid treatment has also been found to affect other systems, including the renin-angiotensin system (Dodic et al. 2002), that are also likely to be involved.

In conclusion, glucocorticoids are affected by NR in both the sheep and rat models. These changes could explain some of the differences seen in the GH-IGF and PG axes thereby providing a potential mechanism for their programming.

\section{Acknowledgements}

K.A.B. was supported by a University of Nottingham Postgraduate Scholarship and a training grant from the Canadian Institutes of Health Research.

\section{References}

Audoly LP, Tilley SL, Goulet J, Key M, Nguyen M, Stock JL, McNeish JD, Koller BH \& Coffman TM (1999) Identification of specific EP receptors responsible for the hemodynamic effects of PGE2. American Journal of Physiology 277, H924H930.

Barker DJ (2002) Fetal programming of coronary heart disease. Trends in Endocrinology and Metabolism 13, 364-368.

Barker DJ, Bull AR, Osmond C \& Simmonds SJ (1990) Fetal and placental size and risk of hypertension in adult life. British Medical Journal 301, 259-262.

Bauer MK, Breier BB, Bloomfield FH, Jensen EC, Gluckman PD \& Harding JE (2003) Chronic pulsatile infusion of growth hormone to growth-restricted fetal sheep increases circulating fetal insulin-like growth factor-I levels but not fetal growth. Journal of Endocrinology 177, 83-92.

Bauer MK, Harding JE, Breier BH \& Gluckman PD (2000) Exogenous GH infusion to late-gestational fetal sheep does not alter fetal growth and metabolism. Journal of Endocrinology 166, 591-597.

Bertram C, Trowern AR, Copin N, Jackson AA \& Whorwood CB (2001) The maternal diet during pregnancy programs altered expression of the glucocorticoid receptor and type 211 betahydroxysteroid dehydrogenase: Potential molecular mechanisms underlying the programming of hypertension in utero. Endocrinology 142, 2841-2853.

Bispham J, Gopalakrishnan GS, Dandrea J, Wilson V, Budge H, Keisler DH, Broughton Pipkin F, Stephenson T \& Symonds ME (2003) Maternal endocrine adaptation throughout pregnancy to nutritional manipulation: consequences for maternal plasma leptin and cortisol and the programming of fetal adipose tissue development. Endocrinology 144, 3575-3585.
Brameld JM, Mostyn A, Dandrea J, Stephenson TJ, Dawson JM, Buttery PJ \& Symonds ME (2000) Maternal nutrition alters the expression of insulin-like growth factors in fetal sheep liver and skeletal muscle. Journal of Endocrinology 167, 429-437.

Brennan KA, Gopalakrishnan GS, Kurlak L, Rhind SM, Kyle CE, Brooks AN, Rae MT, Olson DM, Stephenson T \& Symonds ME (2005) Impact of maternal undernutrition and fetal number on glucocorticoid, growth hormone and insulin-like growth factor receptor mRNA abundance in the ovine fetal kidney. Reproduction 129, 151-159.

Breyer MD \& Breyer RM (2000) Prostaglandin E receptors and the kidney. American Journal of Physiology 279, F12-F23.

Budge H, Dandrea J, Mostyn A, Evens Y, Watkins R, Sullivan C, Ingleton P, Stephenson T \& Symonds ME (2003) Differential effects of fetal number and maternal nutrition in late gestation on prolactin receptor abundance and adipose tissue development in the neonatal lamb. Pediatric Research 53, 302-308.

Campean V, Theilig F, Paliege A, Breyer M \& Bachmann S (2003) Key enzymes for renal prostaglandin synthesis: sitespecific expression in rodent kidney (rat, mouse). American Journal of Physiology 285, F19-F32.

Catella-Lawson F, McAdam B, Morrison B, Kapoor S, Kujubu D, Antes L, Lasseter K, Quan H, Gertz B \& FitzGerald G (1999) Effects of specific inhibition of cyclooxygenase-2 on sodium balance, hemodynamics, and vasoactive eicosanoids. Journal of Pharmacology and Experimental Therapeutics 289, 735-741.

Devarajan P \& Benz EJ (2000) Translational regulation of Na-K-ATPase subunit mRNAs by glucocorticoids. American Journal of Physiology 279, F1132-F1138.

Dilger K, Herrlinger C, Peters J, Seyberth HW, Schweer H \& Klotz U (2002) Effects of celecoxib and diclofenac on blood pressure, renal function, and vasoactive prostanoids in young and elderly subjects. Journal of Clinical Pharmacology $\mathbf{4 2}$ 985-994.

Dinchuk JE, Car BD, Focht RJ, Johnston JJ, Jaffee BD, Covington MB et al. (1995) Renal abnormalities and an altered inflammatory response in mice lacking cyclooxygenase II. Nature 378, 406-409.

Dodic M, Hantzis V, Duncan J, Rees S, Koukoulas I, Johnson K, Wintour EM \& Moritz K (2002) Programming effects of short prenatal exposure to cortisol. FASEB Journal 16, 1017-1026.

Edwards LJ \& McMillen IC (2002) Impact of maternal undernutrition during the periconceptional period, fetal number, and fetal sex on the development of the hypothalamo-pituitary adrenal axis in sheep during late gestation. Biology of Reproduction 66, 1562-1569.

Franco MCP, Arruda RMMP, Fortes ZB, Oliveira SF, Carvalho MHC, Tostes RCA \& Nigro D (2002) Severe nutritional restriction in pregnant rats aggravates hypertension, altered vascular reactivity, and renal development in spontaneously hypertensive rats offspring. Journal of Cardiovascular Pharmacology 39, 369-377.

Fulton M, Adams W, Lutz W \& Oliver MF (1978) Regional variations in mortality from ischaemic heart and cerebrovascular disease in Britain. British Heart Journal 40, 563-568.

Gardner DS, Jackson AA \& Langley-Evans SC (1997) Maintenance of maternal diet-induced hypertension in the rat is dependent on glucocorticoids. Hypertension 30, 1525-1530.

Gardner DS, Jamall E, Fletcher AJ, Fowden AL \& Giussani DA (2004a) Adrenocortical responsiveness is blunted in twin relative to singleton ovine fetuses. Journal of Physiology 557, 1021-1032.

Gardner DS, Pearce S, Dandrea J, Walker R, Ramsay MM, Stephenson T \& Symonds ME (2004b) Peri-implantation 
undernutrition programs blunted angiotensin II evoked baroreflex responses in young adult sheep. Hypertension 43, 12901296.

Gertz BJ, Krupa D, Bolognese JA, Sperling RS \& Reicin A (2002) A comparison of adverse renovascular experiences among osteoarthritis patients treated with rofecoxib and comparator non-selective non-steroidal anti-inflammatory agents. Current Medical Research and Opinion 18, 82-91.

Gleason CA (1987) Prostaglandins and the developing kidney. Seminars in Perinatology 11, 12-21.

Gopalakrishnan GS, Gardner DS, Dandrea J, Langley-Evans SC, Pearce S \& Kurlak LO et al. (2005) Influence of maternal pre-pregnancy body composition and diet during early-mid pregnancy on cardiovascular function and nephron number in juvenile sheep. British Journal of Nutrition (In the Press).

Gopalakrishnan GS, Gardner DS, Rhind SM, Rae MT, Kyle CE, Brooks AN, Walker RM, Ramsay MM, Keisler DH, Stephenson T \& Symonds ME (2004) Programming of adult cardiovascular function after early maternal undernutrition in sheep. American Journal of Physiology 287, R12-R20.

GoppeltStruebe M (1997) Molecular mechanisms involved in the regulation of prostaglandin biosynthesis by glucocorticoids. Biochemical Pharmacology 53, 1389-1395.

Hammerman MR (1989) The growth hormone insulin-like growth-factor axis in kidney. American Journal of Physiology 257, F503-F514.

Hammerman MR \& Miller SB (1993) The growth-hormone insulin-like growth-factor axis in kidney revisited. American Journal of Physiology 265, F1-F14.

Hinchliffe SA, Lynch MR, Sargent PH, Howard CV \& Van Velzen D (1992) The effect of intrauterine growth retardation on the development of renal nephrons. British Journal of Obstetrics and Gynaecology 99, 296-301.

Hochberg Z (2002) Mechanisms of steroid impairment of growth. Hormone Research 58, 33-38.

Holt RIG (2002) Fetal programming of the growth hormoneinsulin-like growth factor axis. Trends in Endocrinology and Metabolism 13, 392-397.

Hyatt MA, Walker DA, Stephenson T \& Symonds ME (2004) Ontogeny and nutritional manipulation of the hepatic prolactingrowth hormone-insulin-like growth factor axis in the ovine fetus and in neonate and juvenile sheep. Proceedings of the Nutrition Society 63, 127-135.

Ishibe Y, Shiokawa Y, Umeda T, Uno H, Nakamura M \& Izumi T (1998) Prostaglandin E1 antagonizes hypoxic pulmonary vasoconstriction but reduces systemic blood pressure in dogs. Critical Care Medicine 26, 126-131.

Jensen BL, Stubbe J, Hansen PB, Andreasen D \& Skott O (2001) Localization of prostaglandin E-2 EP2 and EP4 receptors in the rat kidney. American Journal of Physiology 280, F1001F1009.

Jensen R, Armitage JA, Athauda S, Preston J, Poston L \& Taylor PD (2005) Cardiovascular radiotelemetric monitoring and aortic function in adult rats exposed to protein restriction in utero. Journal of the Society for Gynecologic Investigation (In the Press).

Johnson AG, Nguyen TV \& Day RO (1994) Do nonsteroidal antiinflammatory drugs affect blood pressure? A meta-analysis. Annals of Internal Medicine 121, 289-300.

Johnson RF, Mitchell CM, Clifton V \& Zakar T (2004) Regulation of 15-hydroxyprostaglandin dehydrogenase (PGDH) gene activity, messenger ribonucleic acid processing, and protein abundance in the human chorion in late gestation and labor. Journal of Clinical Endocrinology and Metabolism 89, $5639-5648$

Kailasam MT, Lin MC, Cervenka JH, Parmer RJ, Kennedy BP, Ziegler MG \& O'Connor DT (1994) Effects of an oral prostaglandin E1 agonist on blood pressure and its determinants in essential hypertension. Journal of Human Hypertension 8, 515-520.

Knox EG (1973) Ischaemic-heart-disease mortality and dietary intake of calcium. Lancet i, 1465-1467.

Komhoff M, Wang JL, Cheng HF, Langenbach R, McKanna JA, Harris RC \& Breyer MD (2000) Cyclooxygenase-2-selective inhibitors impair glomerulogenesis and renal cortical development. Kidney International 57, 414-422.

Konje JC, Bell SC, Morton JJ, de Chazal R \& Taylor DJ (1996) Human fetal kidney morphometry during gestation and the relationship between weight, kidney morphometry and plasma active renin concentration at birth. Clinical Science (London) 91, 169-175.

Langley SC \& Jackson AA (1994) Increased systolic blood pressure in adult rats induced by fetal exposure to maternal low protein diets. Clinical Science (London) 86, 217-222.

Langley-Evans SC, Welham SJM \& Jackson AA (1999) Fetal exposure to a maternal low protein diet impairs nephrogenesis and promotes hypertension in the rat. Life Sciences $\mathbf{6 4}$, 965-974.

Lemmer B, Witte K, Schanzer A \& Findeisen A (2000) Circadian rhythms in the renin-angiotensin system and adrenal steroids may contribute to the inverse blood pressure rhythm in hypertensive TGR(mREN-2)27 rats. Chronobiology International 17, 645-658.

Lesage J, Blondeau B, Grino M, Breant B \& Dupouy JP (2001) Maternal undernutrition during late gestation induces fetal overexposure to glucocorticoids and intrauterine growth retardation, and disturbs the hypothalamopituitary adrenal axis in the newborn rat. Endocrinology 142, 1692-1702.

Lucas SRR, Silva VLC, Miraglia SM \& Gil FZ (1997) Functional and morphometric evaluation of offspring kidney after intrauterine undernutrition. Pediatric Nephrology 11, 719-723.

McMullen S, Gardner DS \& Langley-Evans SC (2004) Prenatal programming of angiotensin II type 2 receptor expression in the rat. British Journal of Nutrition 91, 133-140.

Mackenzie H \& Brenner B (1995) Fewer nephrons at birth: a missing link in the etiology of essential hypertension? American Journal of Kidney Disease 26, 91-98.

Madsen K, Stubbe J, Yang T, Skott O, Bachmann S \& Jensen BL (2004) Low endogenous glucocorticoid allows induction of kidney cortical cyclooxygenase-2 during postnatal rat development. American Journal of Physiology 286, F26-F37.

Matson JR, Stokes JB \& Robillard JE (1981) Effects of inhibition of prostaglandin synthesis on fetal renal-function. Kidney International 20, 621-627.

Mitchell EK, Louey S, Harding R, Cock ML \& Black MJ (2003) Growth retardation in utero due to twinning: effect on nephron endowment. Pediatric Research 53, 46A.

Moritz KM, Dodic M \& Wintour EM (2003) Kidney development and the fetal programming of adult disease. Bioessays $\mathbf{2 5}$, 212-220.

Nasjletti A, Erman A, Cagen L \& Baer P (1984) Plasma concentrations, renal excretion, and tissue release of prostaglandins in the rat with dexamethasone-induced hypertension. Endocrinology 114, 1033-1040.

Ogawa T, Tomomasa T, Hikima A, Kobayashi Y, Nakano K, Fukabori Y \& Morikawa A (2001) Developmental changes in cyclooxygenase mRNA expression in the kidney of rats. Pediatric Nephrology 16, 618-622.

Osmond C, Barker DJ \& Slattery JM (1990) Risk of death from cardiovascular disease and chronic bronchitis determined by place of birth in England and Wales. Journal of Epidemiology and Community Health 44, 139-141.

Ozaki T, Nishina H, Hanson MA \& Poston L (2001) Dietary restriction in pregnant rats causes gender-related hypertension 
and vascular dysfunction in offspring. Journal of Physiology 530, 141-152.

Parving H, Noer I, Mogensen C \& Svendsen P (1978) Kidney function in normal man during short-term growth hormone infusion. Acta Endocrinologica 89, 796-800.

Pocock SJ, Shaper AG, Cook DG, Packham RF, Lacey RF, Powell P \& Russell PF (1980) British Regional Heart Study: geographic variations in cardiovascular mortality, and the role of water quality. British Medical Journal 280, 1243-1249.

Pope JE, Anderson JJ \& Felson DT (1993) A meta-analysis of the effects of nonsteroidal anti-inflammatory drugs on blood pressure. Archives of Internal Medicine 153, 477-484.

Potter EL (1972) Normal and Abnormal Development of the Kidney. Chicago, IL: Year Book Medical Publishers.

Rogers SA, Powell-Braxton L \& Hammerman MR (1999) Insulin-like growth factor I regulates renal development in rodents. Developmental Genetics 24, 293-298.

Schweda F, Klar J, Narumiya S, Nusing RM \& Kurtz A (2004) Stimulation of renin release by prostaglandin E2 is mediated by EP2 and EP4 receptors in mouse kidneys. American Journal of Physiology 287, F427-F433.

Sherman RC, Jackson AA \& Langley-Evans SC (1999) Longterm modification of the excretion of prostaglandin E-2 by fetal exposure to a maternal low protein diet in the rat. Annals of Nutrition and Metabolism 43, 98-106.

Tilley SL, Audoly LP, Hicks EH, Kim HS, Flannery PJ, Coffman TM \& Koller BH (1999) Reproductive failure and reduced blood pressure in mice lacking the EP2 prostaglandin E-2 receptor. Journal of Clinical Investigation 103, 1539-1545.

Tonkiss J, Trzcinska M, Galler JR, Ruiz-Opazo N \& Herrera VLM (1998) Prenatal malnutrition-induced changes in blood pressure - Dissociation of stress and nonstress responses using radiotelemetry. Hypertension 32, 108-114.

Vio CP, Balestrini C, Recabarren M \& Cespedes C (1999) Postnatal development of cyclooxygenase-2 in the rat kidney. Immunopharmacology 44, 205-210.

Wada J, Liu ZZ, Alvares K, Kumar A, Wallner E, Makino H \& Kanwar YS (1993) Cloning of cDNA for the alpha-subunit of mouse insulin-like growth factor-I receptor and the role of the receptor in metanephric development Proceedings of the National Academy of Sciences USA 90, 10360-10364.

Whorwood CB, Firth KM, Budge H \& Symonds ME (2001) Maternal undernutrition during early to midgestation programs tissue-specific alterations in the expression of the glucocorticoid receptor, 11 beta-hydroxysteroid dehydrogenase isoforms, and type 1 angiotensin II receptor in neonatal sheep. Endocrinology 142, 2854-2864.

Williams SJ, McMillen IC, Zaragoza DB \& Olson DM (2002) Placental restriction increases the expression of prostaglandin endoperoxide $\mathrm{G} / \mathrm{H}$ synthase-2 and EP2 mRNA in the fetal sheep kidney during late gestation. Pediatric Research 52, 879-885.

Williams SJ, Olson DM, Zaragoza DB, Coulter CL, Butler TG, Ross JT \& McMillen IC (2004) Cortisol infusion decreases renin, but not PGHS-2, EP2, or EP4 mRNA expression in the kidney of the fetal sheep at days 109-116. Pediatric Research $\mathbf{5 5}, 637-644$.

Woods LL, Ingelfinger JR \& Rasch R (2005) Modest maternal protein restriction fails to program adult hypertension in female rats. American Journal of Physiology (In the Press).

Woods LL \& Weeks DA (2005) Prenatal programming of adult blood pressure: role of maternal corticosteroids. American Journal of Physiology (In the Press).

Yao B, Harris RC \& Zhang MZ (2005) Interactions between 11beta-hydroxysteroid dehydrogenase and COX-2 in kidney. American Journal of Physiology 288, R1767-R1773.

Ymer SI \& Herington AC (1992) Developmental expression of the growth-hormone receptor gene in rabbit-tissues. Molecular and Cellular Endocrinology 83, 39-49.

Zhang M-H, Harris RC \& McKanna JA (1999) Regulation of cyclooxygenase-2 (COX-2) in rat renal cortex by adrenal glucocorticoids and mineralocorticoids. Proceedings of the National Academy of Sciences USA 96, 15280-15285.

Zhang MZ, Hao CM, Breyer MD, Harris RC \& McKanna JA (2002) Mineralocorticoid regulation of cyclooxygenase-2 expression in rat renal medulla. American Journal of Physiology 283, F509-F516. 